Discourse and Communication for Sustainable Education, vol. 8, no. 2, pp. 38-56, 2017

\title{
Empathetic Design: A Sustainable Approach to School Change
}

\author{
Rita J. Hartman, Elizabeth Johnston, and Marty Hill \\ University of Phoenix, The United States of America
}

\begin{abstract}
A descriptive case study approach is employed using a content analysis of the blogs of 36 school leaders who took part in the 2016-2017 Shadow a Student Challenge project and follow up interviews of five of the school leaders. This research was used to explore and describe how an empathetic design approach provided a greater vantage point for school leaders. By viewing school through the eyes of students, school leaders gain a deeper insight into the school experience. School leaders play a key role in establishing the culture, climate, and educational outcomes within their school environments. An empathetic design approach to school reform provides a stronger point for initiating change than an atmosphere focused on evaluation and accountability. Taking a schoolbased approach, encouraging school leaders to immerse themselves in the school experience, provides an opportunity for school leaders to gain empathy and insights foundational in generating meaningful and innovative change leading to sustainable education. Three major themes emerged from the findings: 1) pace and structure of the school day, 2 ) student learning experience, and 3) reflective and innovative insights.

Keywords: empathetic design thinking, school reform, school leadership, constructivism, socio-cultural theory, sustainable education.
\end{abstract}

\section{Introduction}

Despite the efforts of the federal mandated law No Child Left Behind (U.S. Department of Education, 2001) and the Common Core State Standards (Common Core State Standards Initiative, 2017; National Governors Association Center for Best Practices, Council of Chief State School Officers, 2010) to increase student achievement and graduation rates, both initiatives have met with limited and mixed results (Duckworth, Quinn, \& Tsukayama, 2012; Eppley, 2015; Husband \& Hunt, 2015; Tienken \& Orlich 2013). Students who dropped out of high school faced a 49 percent unemployment rate in 2015 (National Center for Educational Statistics, 2017) generating a socio-economic impact on their lifestyle and on the local, state, and federal support systems for those individuals and families who lived below the poverty level (Barry \& Reschely, 2012). Some of the factors that influenced the rate of high school non-completion have been 
identified as the low socio-economic status of the family, single parent families, poor academic success in school, high absenteeism, and high mobility rate (Barton, 2006).

Addressing family economic status, family structure, and the mobility rate of families with the intent of reducing the dropout rate may be difficult. Alternately, leaders who gain a stronger understanding of the school structure, culture, and climate could influence a student's decision to remain and be academically successful in school through graduation (Kearney \& Levine, 2016; Kosar, Kosar, \& Ogdem, 2016; Smith \& Thomson, 2014). The practice of initiating system change based on deeper understanding of system users needs is called empathetic design. Positive change can occur when principals, who are leaders within their school and have the capacity to effect change within the system, observe and share student daily experiences. Understanding and acting on empathic understandings of the students may help school leaders to build a structure, culture, and climate that supports greater student success and increased high school graduation rates.

\section{Theoretical Framework and Literature Review}

Studies in business and health care explored the potential of empathetic design in business organizations where customers were observed in their own environment as an approach to gathering and analyzing information and using what is learned to apply towards future actions (Carmel-Gilfilen \& Portillo, 2016; Daniel, 2015; Eslamifar, 2014; Kolko, 2010; Leonard, \& Rayport, 1997). Existing research demonstrated the value of being empathetic to individual experiences and the informational frame in the learning process. Allowing leaders, who understand system capacity for change, to personally experience the student classroom conditions sets up a potential for innovation.

Aligned with empathetic design is the concept of social cultural theory where meaning evolves through social interactions within a specific culture (Bokova \& Pluzhnikova, 2016; Packer \& Goicoechea, 2000). Zygmunt's (2016) research study reinforced the importance of sharing experiences and information through discourse leading to a rise in consciousness and understanding within a bounded culture. Along with social cultural theory is the concept of constructivism where meaning is constructed through an experience (Barrett \& Long, 2012; Mishra, 2014). El-Deghaidy's (2012) study focused on the importance of constructivism from the perspective of teachers' as researchers; however, the findings can be applied to school leaders who take an active role in constructing knowledge through personal experiences within the school culture. Social constructivism is the process where the individual constructs meaning and knowledge through social interactions (Fleury \& Garrison, 2014; Walker \& Shore, 2015). School leaders could find benefits in using empathetic design principles to gain a deeper understanding of the social culture in which students construct meaning leading to an "empathetic, critical integration of multiple perspectives" (Daniel, 2015, para 1). The findings from the present study provided insights into how the knowledge from empathetic design, social culture theory, and constructivist theory could be utilized by school leaders in becoming active participants in the students school experience, providing real time culturally responsive pedagogy (Daniel, 2015). 


\section{Statement of the Problem}

The Shadow a Student Challenge, an initiative of the School Retool effort and in partnership with William + Flora, Hewlett Foundation, and the Innovation, Design Engineering Organization, known as IDEO, encourages school leaders to spend the day with a student to gain insights and a deeper empathy for the daily experiences of a student as they navigate the curriculum, schedule, and expectations of school life (shadowastudent.org). The project is an international movement to drive school change as a result of the understandings and reflections shared by school leaders who follow a student from the beginning of their day to the end of their day. In 2016-2017, the second year of the project, school leaders in 55 countries and all 50 states took up the Shadow a Student Challenge (shadowastudent.org). The Challenge involved a fourstep process; school leaders prepare, shadow, reflect, and act (shadowastudent.org). This study focuses on the reflections of the school leaders who took part in the Challenge during the 2016-2017 school year.

The problem is that although businesses have used empathetic design effectively, little is known about how empathic design might work to improve outcomes in a school setting. The purpose of the descriptive case study was to understand how school leaders characterize their experiences when shadowing a student for the day. The study involved an in-depth exploration of school leaders' experiences, thus gaining an understanding and generating a detailed description of the experiences (Yin, 2013). A content analysis was conducted on data collected from 36 online public blogs where school leaders reflected on their shadowing experience followed by a content analysis of the transcripts of phone interviews with five of the participants. Comments from the project leader were a third point of data.

\section{Research Questions}

The following research questions were asked to assist in addressing the problem: How did school leaders construct meaning from spending the day shadowing a student?

SRQ 1: What experiences do school leaders share about their Shadow a Student Challenge that reflects on the pace and structure of the students' learning experience?

SRQ2: What can be learned from students' interactions (or lack thereof) in the classroom environment from the observations of the school leaders?

SRQ3: How did school leaders characterize reflective and innovative insights after shadowing a student for the day?

\section{Method}

\section{Research design}

This study used a descriptive case study approach employing a content analysis of the generated text. A descriptive case study approach provided a rich description of the phenomenon under study (Merriam, 2009; Yin, 2013) and using a content analysis was appropriate for analyzing the blog text and the narrative interview transcripts for themes and patterns (Merriam, 2009; Vaismoradi, Turunen, \& Bondas, 2013). The inductive analysis was conducted on narrative data collected from 36 online public blogs where 
school leaders reflected on their shadowing experiences followed by an analysis of the transcripts of phone interviews with the project leader and five of the participants.

\section{Setting, population, sample}

The geographic setting is the online environment. The text for the content analysis was retrieved from the public blogs of thirty-six school leaders who voluntarily posted their reflections after shadowing a student for the day as part of the Shadow a Student Challenge conducted during the 2016-2017 school year. School leaders were considered to be school principals or other individuals in the school system that were perceived as leaders at their school site and were familiar with the student population. The project leader and a purposeful sample of five school leaders drawn from the population took part in phone interviews to increase the reliability of the findings. The individuals meet the criteria of the present study to understand and describe the school leaders' perceptions of their day shadowing a student. The qualitative, content analysis allowed researchers to analyze narrative text drawn from a naturalistic setting exploring and describing the construction of personal meaning (Hsieh \& Shannon, 2005).

\section{Sampling}

The-selected sample of participants were those who had direct experience with a student's day, have empathetic design thinking experience, and who were school leaders.

\section{Recruiting the sample}

The Shadow a Student Challenge project leader provided the researchers with permission to post a note on the Challenge website inviting school leaders who took part in the Challenge to a follow up phone interview with the researchers. Using a purposive process, five school leaders who reported innovations stemming from their shadowing experiences were invited to participate in a phone interview. Of the five who were interviewed, two were female and three were male. Interview participant roles were a superintendent, three principals, and an assistant principal. The project leader, a female, provided insights into the project through personal communication.

\section{Blog Sample}

The 36 blog entries comprised the sample of public data drawn for the content analysis stage of the research. Twenty-one men and fifteen women shared personal experiences, observations, and reflections on how the shadowing experience affected their perceptions. The average word count for blogs was 1025 words per blog (total 36915 ), ranging from 263 to 2706 words. The school leaders who published blogs included 2 superintendents, 26 principals/assistant principals, and 8 Head Teachers/ Supervisors. Schools represented were 6 elementary schools, 13 middle/junior high schools, 14 high schools, 2 K-12 schools, and 1 unknown. 


\section{Procedure}

\section{Data collection}

Personal desktop and laptop computers were used to gather existing public content. In the first phase of this study, narrative text was collected from online public blogs and downloaded into a Google Doc. Duggan (2013) suggested the use of narrative analysis gathered from online blogs is similar to face-to-face recounting of events. The online blog space provided a different avenue or frame for participants to reflect and generate a narrative discussion on the Shadow a Student Challenge. Content was gathered from the Shadow a Student Challenge website (shadowastudent.org). The names of the authors of the blogs were removed and replaced with the code of P1 through to P36.

\section{Procedures for analysis}

In qualitative content the most effective analysis is where little to no preexisting theories exists, and an inductive process of open coding leads to a list of categories, themes, or patterns describing the phenomenon and providing an interpretation (Elo \& Kyngäs, 2008). Researchers followed the process outlined by Johnston, Rasmusson, Foyil, and Shopland (2017) of developing a holistic understanding as each team member analyzed the blogs individually and collaboratively using a content analysis approach of coding, categorizing, and managing the analysis to identify emerging themes and patterns from the blogs. In the early steps of analysis, four different markers were useful to color code words and phrases in text related to specific research questions. The researchers reviewed the outcomes of the blog narratives to assess the extent the concepts related to empathetic design, socio-cultural theory, and constructivism. The result of the blog analysis was used to develop follow up interview questions for the project leader and five individuals purposively drawn from the larger sample of 36 school leaders. Follow up interviews allowed us to verify the findings, and to gain a deeper understanding into the experience.

Focused phone interviews provided corroboration for the findings from the content analysis of the blog narratives and generated new insights and new perspectives (Yin, 2013). Participants who responded to the note posted on the Shadow a Student Challenge website, by emailing the researchers, were informed of the purpose of the study and the process. Once participants agreed to be interviewed, they were provided with a Consent Form that was signed and returned to the researchers. A day and time for the phone interviews was determined and scheduled. Participants were provided with the interview questions prior to the interview, to allow for reflection and careful thought before the actual interview. All three researchers took notes during the interviews and compared and combined notes into comprehensive transcripts. A member's check was conducted giving each participant a transcript of the conversation to ensure validate and reliability of the interview notes (Merriam, 2009; Yin, 2013). One participant provided clarification of her response to the first question, and her revisions were included in the final transcript of her interview. 


\section{Results and Discussion}

The results are presented by sub questions to the main research question: How did school leaders construct meaning from spending the day shadowing a student?

\section{Sub-question one}

What experiences do school leaders share about their Shadow a Student Challenge that reflects on the pace and structure of the students' learning experiences?

Responses from 26 school leaders' blogs that related specifically to the pace and structure of the students' learning experiences were identified.

Table 1 provides codes and comments for the theme of comfort. Four codes emerged: hunger, sitting, exhausted, and stress. School leaders' reflections expressed concerns over the lunch as the only time for nourishment, distress and exhaustion created by having to sit for long periods of time, and other challenges related to physical needs.

Table 1

School Leaders' Reflections on Pace and Structure: Comfort

Theme: Comfort - Codes: hunger, sitting, exhausted, stressed

Code: hunger

\begin{tabular}{|c|c|}
\hline P1 & Lunch time (thank goodness, I was so hungry) \\
\hline $\mathrm{P} 2$ & $\begin{array}{l}\text { attempting to pay attention, I can only think about making it down to my office to get } \\
\text { my almonds and water bottle }\end{array}$ \\
\hline P3 & some kids begin to ask what's for lunch \\
\hline P4 & Where's my coffee? I miss it. Wondering if students miss their morning beverage too, \\
\hline $\mathrm{P} 4$ & finally Lunch \\
\hline P8 & I need a snack around 9:30am \\
\hline P18 & $\begin{array}{l}\text { I also was really hungry! I ate breakfast at 7:15 a.m. and went close to four hours before } \\
\text { eating lunch }\end{array}$ \\
\hline \multicolumn{2}{|c|}{ Code: sitting } \\
\hline P4 & $\begin{array}{l}\text { students and faculty sit for a half hour... can be difficult for many students.... my student } \\
\text { has trouble sitting quietly for } 5 \text { minutes }\end{array}$ \\
\hline $\mathrm{P} 4$ & my student, and in fact all the others, really seem comfortable in the space \\
\hline P5 & $\begin{array}{l}\text { We sat... a lot. Sitting during class is exhausting... and some of those desks are so } \\
\text { uncomfortable! }\end{array}$ \\
\hline P8 & Sitting for 50 minutes is hard \\
\hline P9 & $\begin{array}{l}\text { how the students felt about the amount of time they [students] spend sitting versus } \\
\text { standing while engaged in learning over a } 41 \text { minute period. }\end{array}$ \\
\hline P18 & $\begin{array}{l}\text { sitting in a desk was really hard for me. At times, I found myself fidgeting and unsettled } \\
\text { physically }\end{array}$ \\
\hline P25 & $\begin{array}{l}\text { There isn't a lot of movement for our students during the day. It was evident to me that } \\
\text { we need to try to incorporate more time for movement in our classes, especially in our } \\
\text { block classes. I really believe that will help improve student engagement and if done } \\
\text { properly, I think that students will be able to focus better for shorter periods of time and } \\
\text { will actually produce better work samples. }\end{array}$ \\
\hline P29 & $\begin{array}{l}\text { Lots of sitting on hard plastic chairs and in uncomfortable desks. Few opportunities for } \\
\text { students to get up and move, other than between classes }\end{array}$ \\
\hline
\end{tabular}


Sequel to Table 1.

P30 Kids need to move.

Realize why students get bored - taking notes a lot.

Felt like I wouldn't have missed much if I weren't there.

Typical from when we remember our own schooling.

Code: exhausted

P5 The transitions are difficult and draining

P11 Staying engaged for a 7:45 a.m. class was going to be a tall task, even after a couple cups of coffee

P22 Students generally are asked to sit at a desk for the majority of lessons and is quite exhausting.

P30 I am starting to daydream. Final Bell: I'm exhausted.

P33 It was a busy day, and I was certainly tired. those little minds get quite a bit thrown at them throughout the day, on top of just juggling being a 9-year-old!

Code: stress

P4 Certain weeks can become overwhelming to the students when there are increased levels of pressure put on by impending assessments, due dates, and extra-curricular stressors.

P10 Lunch is crowded, but a place where students can relax.

P11 After a full day of school, the real work begins. There is homework to be completed, a paper to be written, a test to be studied for. The steady stream of work can feel relentless, and the teachers always seem to find a way to give tests on the same day

P18 Learning Lab provided quiet time and space... Great time to focus on my specific needs, and I see why it is one of the students' favorite classes

Table 2 provides codes and comments on the second theme of structure. Four codes emerged: rushing, disruptive, lunch, and recess. School leaders shared reflections on the challenges of the day being driven by a rigorous bell schedule, a long school day, a lack of transitions, pressure to meet deadlines and to be ready for assessments, and hectic, quickly moving classes.

Table 2

School Leaders' Reflections on Pace and Structure: Schedule

Theme: Schedule - Codes: time, rushing

Code: time

\begin{tabular}{ll}
\hline P2 & rigorous schedule and course load \\
\hline P4 & before I know it, the bell rings. It wasn't enough time. \\
\hline P5 & very abrupt breaks and transitions throughout the day, dictated by the bell schedule \\
\hline P8 & I am not used to a bell driving my daily schedule \\
\hline P10 & Again, I made it to class on time \\
\hline P11 & Being a student is a full-time job. The hours are long, \\
\hline P11 & The work doesn't end at the end of the school day. \\
\hline P13 & What I found challenging...Getting to class on time. \\
\hline P19 & I found it to be a very long day \\
\hline P24 & $\begin{array}{l}\text { time management and be able to prioritize to be successful in high school. This includes } \\
\text { being prepared }\end{array}$ \\
\hline
\end{tabular}


Sequel to Table 2.

P30 Surprised by amount of time to relax -20 minutes.

P32 children are engaged in learning activities from the start of the day to when they say their goodbyes at the door (recess was really the only unstructured time they had).

Code: rushing

P11 Just as I was beginning to understand the philosophy of philanthropy, the bell rang and I was ushered down the hall by a steady stream of students to my next class. I had four minutes to reach my destination and switch gears from history to science.

P15 It's easy to forget that a student's day is more hectic that we, as adults, tend to remember. There was a lot to do throughout the day; with eight 47-minute periods, a student schedule moves along quickly.

P16 One thing I recognized in all the classes is that you better keep up. They move fast and expect students to have their work and be ready to go. My student left with homework... I was just glad I didn't have to turn my work in tomorrow

P30 Every minute was planned - felt rushed

\section{Sub-question two}

What can be learned from students' interactions (or lack thereof) in the classroom environment from the observations of the school leaders?

Three themes emerged from the blogs of 17 of the school leaders relative to research sub-question two; teaching strategies, community, leader experiences of student pressures.

Table 3 includes the code engagement, which surfaced under the theme of teaching strategies. The reflections of the school leaders included the absence of student voices, the importance of collaboration and sharing, and the different ways learning can look.

Table 3

School Leaders' Reflections on Student Learning Experiences: Teaching Strategies

Theme: Meaningful

Code: engagement

P11 Being mentally present is a monumental task.

P17 Student engagement varies through the day and it is OK

P17 The student's perceived engagement level fluctuated. His engagement appeared highest when he applied the content that was being taught.

P17 student engagement appeared lowest when content was being delivered or instructions were being provided. He would rarely focus on the teacher, would play with his sweater, or tinker with a calculator or dry erase marker. I shared my observations with my student, he thought about his response before answering, "I felt a little tired during math (right before lunch time), but I was trying to pay attention."

P17 Ironically, it is what the teacher did not do that may have had the greatest impact. He didn't redirect the student when he was not looking right at him and he did not call his attention when he was playing with his sweater.

P17 It's clear that the student was paying attention, but was doing it in his own way, and his teacher understood this. It's critical to be aware of, and to be OK with, the reality that students listen and learn in many different ways, and being empathic to their perspective is crucial to helping keep students motivated and engaged in the learning process. 
Sequel to Table 3.

P24 I felt engaged in the learning and the process. But it (learning) looked many different ways. I was engaged when I was quiet, talking, listening, thinking, reading, writing, working individually, collaborating, using technology,

P24 It was amazing how much of an impact laughing had on my engagement

P27 [student] understands that learning (in part) is doing and knows some classes demand more attention, others are worthy of attention, and few require little attention... and she's right

P29 The group project was the only time throughout the day students were allowed to use technology as a tool to explore personalized inquiry in relation to content

P31 The constant conferring between table groups, sharing out with classmates and the teacher's continual monitoring and specific feedback made me feel like I was a mathematician Rockstar!!

P32 High levels of dialogue reflected classroom teaching and demonstrated strong critical and creative thinking

P34 Giving students the skills and little nudges in the direction of working hard helps our students see they can accomplish great things. Our teachers are always making us stretch ourselves, in directions we never knew we could

Table 4 provides the codes of relationships, support, and caring that emerged under the theme of community. Comments from school leaders reflected the importance of relationships among students and among students and teachers and the fact that students care when they know teachers care.

Table 4

School Leaders' Reflections on Student Learning Experiences: Community

Theme: Community - Codes: relationships, support and caring

Code: relationships

P4 There is so much power in the peer-to-peer conversations, relationships, and interactions. I hope everyone keeps that in mind and knows that you can profoundly change someone's day by just acknowledging their presence.

P5 Relationships are so key and to know we are surrounded by others that feel the same is very important to me.

P18 I watched students flow naturally between different social circles in and out of the classroom. It was a community full of joy and appreciation.

P28 But the highlight of the day (for both of us) was something so simple yet so powerful; the highlight of the day was a walk we took right after lunch. I'd take my student for a walk outside during which time she shared some of her future goals and details about her family life. There was so much I didn't know before this experience and wouldn't have known had we not taken the walk. Afterward, she told me she'd like to walk again on a "normal" day

P29 The students were polite and respectful in a very safe environment. It was obvious students were interested in doing well academically. Also, the teachers have good connections and share a mutual respect with their students.

P32 In the classroom I was in, there was a very strong sense of community.

Codes: support and caring

P5 ...when our students are put in very stressful situations, however, there is compassion and understanding surrounding them 
Sequel to Table 4.

P5 From asking about an extra-curricular, to telling a student they were missed when they were absent, our teachers care and try to connect with our students in an effort to forge the all-important relationship and then leverage that in the learning process

P9 I found myself thoroughly appreciating the academic socialization that teachers established as a school culture norm.

P9 The students know, appreciate, and unconditionally value their teachers' strengths, are very willing to honestly share about their teachers' weaknesses, and are overall very accepting of who their teachers are as people.

P13 The students at the school are just so friendly. I was overwhelmed with kind offers from so many different groups of students for me to sit with them at breaks.

P18 I watched students flow naturally between different social circles in and out of the classroom. It was a community full of joy and appreciation.

P20 Our teachers care for our students. In every class period, I was glad to see each and every teacher give individual care and attention to each student.

P25 [Students] like to find ways to talk about what's important to them while still getting work done

P25 Our teachers do some amazing things. They love our kids unconditional

P29 The students were polite and respectful in a very safe environment. It was obvious students were interested in doing well academically. Also, the teachers have good connections and share a mutual respect with their students.

P32 In the classroom I was in, there was a very strong sense of community.

Table 5 provides the codes of anxiety, nervous, and worry that emerged under the theme of student identity. Comments from school leaders reflected a sense of being nervous throughout the day and anxiety over having to go to the bathroom.

Table 5

School Leaders' Reflections on Student Learning Experiences: Leader experiences of student pressures

Theme: Leader experiences of student pressures

Codes related to anxiety, nervous, worry

P4 because I'm an introvert, and I not only cherish, but require quiet reflective periods during the day. I know I'm not going to get that today. Wonder how other introverted kids handle this?

P4 Knowing this anxiety and frustration are real emotions that are felt daily by our students, was a reality check in the experience we provide.

P7 On my way to school, I felt myself getting a bit nervous. The kind of nervous you get on your "first day of school". Worrying about where I would sit, would I know how to answer a question when asked by the teacher?

P7 I was so relieved to see my friend in my first period class. As you know having at least one friend in your class is a huge factor in the amount of "fun" you have in class. I took my seat, as I began my day in Algebra Class... to say I was anxious was an understatement. Math was never a strong content area for me as a student in school. I felt myself hoping that I would not be called on

P7 Then the moment that I had dreaded happened! The teacher called on me to answer a question. I felt my heart begin to race, I felt all eyes turn and stare at me, I took a deep breath and said hesitantly....3? The teacher quickly said... correct! Very good! 
Sequel to Table 5.

P9 The nervous energy, self consciousness, and the uncertainty I felt was all-at-once, consuming. But I sang.

P22 I have a lot more respect and empathy for students once I experienced multiple scenarios that I needed to adapt to.

P24 I actually arrived to a class and had to go to the bathroom, but I chose not to ask to go because I remember the days of being a teacher and saying "why didn't you go during the passing period."

P31 I was in dire need of a restroom, but classroom policy is to wait until the 45 minute break. I tried to pay attention, but I was constantly watching the clock and wondering how can 45 minutes seem so long!

Aye yi yi! Whew, was I glad to make a run to the restroom when our break came!

\section{Sub-question three}

How did school leaders characterize reflective and innovative insights after shadowing a student for the day?

With sub-question three, 23 of the school leaders' responses were connected to the two major themes of reflective insights, thoughtful insights on what was experienced by the individual, and innovative insights, insights that could lead to future actions.

Table 6 provides the theme of reflective insights surfacing through the codes of: related to teaching, students, personal meaning, Shadow a Student experience, and experiencing student identity. School leaders shared empathetic reflections of new understandings gained from the shadowing experience.

Table 6

School Leaders' Reflective Insights: New Understandings

Theme: Reflective Insights - Codes: teaching, students, personal meaning, Shadow a Student experience

Code: teaching

P4 We program kids to do what adults tell them. From the time we start "doing school," we know from grownups that there are rules, and schedules, and behaviors we need to abide by. By the time students reach high school, school has become their job. Go here, go there, do this, do that.

P10 Classes are way more active and engaging then they were when I was in high school, and way more active than when I taught.

P16 As the teacher reviewed with the student, I heard what was my favorite quote of the day, "This class is designed for YOUR success, not mine".

P28 Technology has had a HUGE impact on teaching and learning.

Code: students

P1 I observed that they are brutally honest with each other, don't shy away from controversy, and have plans to make the world a better place.

P1 I had forgotten how passionate young adults can be about politics and felt a little sad that I had lost that excitement and energy when it comes to government.

P9 At this point I realized, the student, who at a glance seems like an ordinary adolescent...is actually quite extraordinary 
Sequel to Table 6.

P9 I came to realize and appreciate exactly how empathetic 12 year-olds can be. They know the difference between right and wrong, and they are able to eloquently express their feelings, more than they're generally given credit for being able to do.

P9 Why did it take me sitting in this class to realize that this is something that our students navigate each and every day, and all that's required, to build empathy, is a willing ear?

P9 I found the students to be unassuming and to find humor in their teachers' idiosyncrasies. In a follow-up conversation with the student, he told me he was surprised because he thought I knew our teachers better.

P11 As teachers and administrators, we can become so consumed with lesson planning, grading papers, and analyzing data that we lose sight of the fact that students are humans, too.

P11 The stresses that come from girlfriends, auditions, or cyber bullying don't pause because class is starting.

P16 Students are intrinsically passionate about learning. If they don't show it, we're not trying hard enough to help them find their passion.

P20 As adults, we sometimes try to quantify or pinpoint aspects of the school we think are important. The reality is that, for the 1,700 students at our High School, everything makes the list.

P23 Our kids are well adjusted, full of creative ideas and really thrive on being successful

P26 Our entire discussion on the way home was about the [award] he received. As I was driving and listening, I looked over and just saw him beaming with joy. It was the perfect end to a perfect day.

P27 She knows some classes demand more of her attention, others are worthy of her attention, and a few require little attention at all. And she's right.

P34 When students are able to experience something they love and enjoy, they want the weekend to pass to get to it. That's pretty cool. We need to help students by creating extra-curricular programs and clubs so they can be excited and see where they "fit in".

Code: personal meaning

P10 It was a positive and powerful experience for me.

P11 The energy of the halls, the relationships with friends and teachers, and the sense of belonging left me feeling fulfilled. I'm not ready to go back though; I'll leave that job to the students.

P16 It was the best day I have spent at work in a long, long time and probably the best professional development I could have experienced.

Code: Shadow a Student Experience

P5 While we were all students too, being reminded of what it was like and seeing it through the lens of a student in 2016 is incredibly important.

P6 as a former math teacher at this level, I can see how this shadow experience would have benefitted me as a teacher...

P6 the process to supervision and evaluation is insignificant compared to the shadowing experience.

P25 I need to shadow a teacher for the day

P27 I believe if every school and systems leader had to be a freshman (or a first grader, sixth grader, or senior) for just one day, our schools would be radically different. Significantly better. Exponentially =more student-centered.

P30 I know that I have colleagues that will support me in my ideas for change. I know this because many of my colleagues echoed the same information during the debriefing session.

P31 Every time we have an opportunity to "walk" in the "shoes" of another we gain perspective. 
Table 7 displays the codes; Learning, student voice, administrative change related to theme of innovative insights. School leaders generated ideas and actions for future changes in their schools as a result of experiences the day as a student.

Table 7

School Leaders' Reflective Insights: Innovative Changes

Theme: Innovative Insights - Codes: Learning, Student Voice, Administrative Change

Code: Learning

P3 I realized that we must show them how to use the devices (cell phones, iPads, etc.) that they are literally connected to in order to learn, investigate, and communicate with others.

P7 What is indisputable is that how time gets used and allocated lies at the heart of reimagining the school experience.

P7 Thus we wonder: how might we reimagine our use of time so that we are even more effective producing "creative thinkers and bold leaders prepared to impact our complex global society?"

But here's the catch: path dependence.

P18 But, it made me realize, in a lot of cases, we as adults find it hard to focus because we are so connected all the time we miss out on some important things going on right in front of our faces. Having no access to my world as principal allowed me to shift gears, to live in the moment, and observe and enjoy the things going on around me.

P24 The takeaway here is that the focus of teaching and learning should be on how to engage students, not how does engagement look. The reality is that it looks many different ways

Code: Student Voice

P8 School needs to look different, structured different. We need to move, trust and give students more freedom in owning their learning

P16 Providing opportunities for increased student voice can help us learn much more about them and can help guide us closer to identifying what they think, feel, and need. How do our students learn best? What are their favorite types of learning experiences? What do they like most about learning?

P16 Students will help us transform our schools if we let them. We just need to look and listen!

P29 Student voices were mostly absent

P29 I wondered how school could become more learner-centered. What if we asked our students how they learn best and made adjustments accordingly? What if we took some time to reflect on what we truly believe about how students learn?

Code: Administrative Change

P6 Examining teaching and learning from the eyes of the student compared to that of an instructional expert was challenging yet rewarding $\sim$ this experience has had a profound impact on my approach to asking questions of educators whom I supervise. I have been maintaining my lens as an evaluator as I visit classes and complete observation reports; however, I am more attentive to the perspective of the student during these visits now and for this I am excited.

P9 Well, for our teachers, the challenge I issued then and issue now, is to be the reason that our students come to school.

P16 It is up to us, as adults in the educational system, to identify innovative ways to meet the needs of our students so that we can help them overcome the barriers over which we have control. We must help each and every one of them identify their passion for learning and celebrate it. 
Sequel to Table 1.

P25 Until I was in the hallway, I didn't see another adult in many of the classes. That is both good and bad. It's good because the teachers are with the kids but it's bad because there is so much that teachers can learn from one another

P30 When a group of professionals band together for change, others begin to listen. I also believe that with my new found opinions of students and what they go through, coupled with the observation notes that I compiled during my experience, I will make a strong case that will resonate with my colleagues enough to get them to think on a different level. I think that I will be able to turn some heads and get some people to look at things in an entirely new perspective.

P30 As a group, they also chose to pose some questions for our district:

How much homework is too much? Do our kids have enough time just to be kids?

How might we better implement cross-disciplinary concepts to avoid teaching and learning in isolation? How can we get kids some reflection time during the day?

\section{Triangulation}

In the current study, triangulation involved a content analysis of school leaders' public blogs, school leaders' interviews, and the project leader's interview. An analysis of the school leaders' public blogs resulted in the emergence of six themes with related codes that were then assessed as to the extent of convergence with the interviews. Findings and sources from the analysis are in Table 8.

Table 8

Summary of Findings and Sources

Research Question:

How did school leaders construct meaning from spending the day shadowing a student?

\begin{tabular}{lll}
\hline \multicolumn{1}{c}{ Sub-question } & \multicolumn{1}{c}{ Findings } & \multicolumn{1}{c}{ Source } \\
\hline SQ1: $\begin{array}{l}\text { Concerns over } \\
\text { pace and } \\
\text { structure }\end{array}$ & $\begin{array}{l}\text { Comfort - hunger, sitting, } \\
\text { exhausted, stress }\end{array}$ & $\begin{array}{l}\text { Blogs, School Leader Interviews, Project } \\
\text { Leader Personal Communication }\end{array}$ \\
\cline { 2 - 3 } $\begin{array}{l}\text { SQ2: } \\
\text { Reflections on } \\
\text { student learning } \\
\text { experiences }\end{array}$ & $\begin{array}{l}\text { Teaching Strategies - } \\
\text { engagement }\end{array}$ & $\begin{array}{l}\text { Blogs, School Leader Interviews, Project } \\
\text { Leader Personal Communication }\end{array}$ \\
\cline { 2 - 3 } & $\begin{array}{l}\text { Community - relationships } \\
\text { and support, caring }\end{array}$ & $\begin{array}{l}\text { Blogs, School Leader Interviews, Project } \\
\text { Leader Personal Communication }\end{array}$ \\
\cline { 2 - 3 } & $\begin{array}{l}\text { Leader experiences of student } \\
\text { pressures - anxiety, nervous, } \\
\text { and worry }\end{array}$ & $\begin{array}{l}\text { Blogs, School Leader Interviews, Project } \\
\text { Leader Personal Communication }\end{array}$ \\
\hline $\begin{array}{l}\text { SQ3: } \\
\text { Reflective and } \\
\text { innovative } \\
\text { insights }\end{array}$ & $\begin{array}{l}\text { Reflective insights - teaching, } \\
\text { students, personal meaning, }\end{array}$ & $\begin{array}{l}\text { Blogs, School Leader Interviews, Project } \\
\text { Leader Personal Communication }\end{array}$ \\
\cline { 2 - 3 } & Shadow a Student experience & \\
\cline { 2 - 3 } & $\begin{array}{l}\text { Innovative insights - learning, } \\
\text { student voice, and administr- } \\
\text { ative change }\end{array}$ & $\begin{array}{l}\text { Blogs, School Leader Interviews, Project } \\
\text { Leader Personal Communication }\end{array}$ \\
\hline
\end{tabular}




\section{Discussion}

The current study is based on the reflections of 36 school leaders who participated in the Shadow a Student Challenge during the 2016-2017 school year. The Challenge project encourages school leaders to spend the day with a student following them from the beginning of the day to the end of the student's day with the goal of using the insight and knowledge gain from the experience to drive change (shadowastudent.org). The study focused on the third step of the process, reflections.

From the school leaders' blogs, several themes emerged from the overarching research question: How did school leaders construct meaning from spending the day shadowing a student? These themes are expanded on in Tables 1-7, and a summary of the findings and sources are displayed in Table 8. School leaders who shadow a student for the day constructed new insights and understandings about the school environment by becoming a part of the student experience. School leaders also acquired a deeper empathy for the students as they immersed themselves in the social cultural educational environment. Major themes concerned the pace and structure of the day, community and teaching strategies, reflections and innovative insights.

Constructing meaning as derived from experience (Barrett \& Long, 2012; Mishra, 2014) was evident in school blogs and reinforced during interviews. School leaders commented on pace and structure of the day noting the discomfort of extended sitting, restricted movement, challenges of transition, and lack of snacks and drinks. Conversely, leaders described the value of moving and feedback, and the unexpectedly engaging aspect of laughing with the class. Comments from P16 and the project director summed it up. "It's easy to forget that a student's day is more hectic than we, as adults, tend to remember" (P16). The project leader commented, "How are we expecting the students to get through the day if we are not meeting their basic needs? The principals would not have understood unless they had gone through the day".

School leaders also constructed meaning related to social interactions (Fleury \& Garrison 2014; Walker \& Shore, 2015) such as community and teaching strategies. The value of group work, critical thinking dialogues, relationships, and academic socialization were mentioned and supported through the blogs and interviews. Research by Irajzad and Shahriari (2017) reinforced the significance of relationships and interpersonal communication on the success and motivation on students. The comment, "Students like to find ways to talk about what's important to them while still getting work done," by P25 expressed the importance of social interactions in the school environment.

In addition, school leaders created reflections and innovative insights derived from the empathetic approach to student perspectives during the Shadow a Student Challenge. School leaders are in a position to effect change within the systems they lead. The goal of experiencing a student day was to gather and analyze information leading to future innovative changes (Carmel-Gilfilen \& Portillo, 2016; Daniel, 2015; Eslamifar, 2014; Kolko, 2010).

Shadow a Student participants raised several questions to initiate innovation. "Thus we wonder: how might we reimagine our use of time at [school] so that we are even more effective producing "creative thinkers and bold leaders prepared to impact our complex global society?” (p. 7). "I wondered how school could become more learnercentered. What if we asked our students how they learn best and made adjustments accordingly? "How much homework is too much? Do our kids have enough time just 
to be kids? How might we better implement cross-disciplinary concepts to avoid teaching and learning in isolation? How can we get kids some reflection time during the day?" (P30). One school leader summarized the insights. "Students will help us transform our schools if we let them. We just need to look and listen!"

The present research study explored and described the experiences and reflections of school leaders who shadowed a student for the day and built on existing literature and research to expand the potential of an innovative approach improving the educational experience for students. Empathetic design as a starting point for change was the focus of the research and will fill a gap in the literature as suggested by several researchers (Khalifa, Gooden, \& Davis, 2016; Maringe, Masinire, \& Nkambule, 2015).

A case study by O'Malley, Long, and King (2015) explored the complexity of responsibilities facing school leaders framed within the context of their school and community. The findings of the study emphasized the importance of school leaders being able to navigate the challenges and tumultuous nature of leading through collaboration being sensitive to multiple perspectives. Khalifa, Gooden, and Davis (2016) built on the importance of empathy as they discussed the impact a culturally responsive school leader can have on school reform. Further, Khalifa, Gooden, and Davis expressed the concern about the lack of research on empathetic design based change initiatives.

Maringe, Masinire, and Nkambule (2015) examined the challenges school leaders faced in schools situated in communities that face multiple challenges and could be considered deprived or impoverished. Leaders need to maintain stability with school staff/ teachers, remain responsive to the community and parents, and engage in a school wide project to energize the whole school community. Leaders need to move from efforts to improve the educational experience, such as curriculum changes, to efforts to improve the school. The suggestion is empathetic leadership and social constructivist sensitivity can drive school improvement for the whole school community. More research with a larger sample is needed to explore inclusive school improvement efforts.

\section{Limitations}

The findings generated from the present study are limited to the scope and qualitative nature of a case study and cannot be generalized to a larger population. The study is also limited to describing the experiences of 36 school leaders who took part in the Shadow a Student Challenge and posted their reflections in a public blog. The findings cannot be used to predict future behaviors (Merriam, 2009). Another limitation could be researcher bias. To assist in mitigating researcher bias, each researcher conducted a content analysis of the narratives from the blogs and the interviews, followed by three to five rounds of collaborative analysis leading to a consensus on the intent and meaning of the school leaders' reflections.

\section{Conclusions}

School leaders constructed new meaning and knowledge by immersing themselves in the school culture and engaging in social interactions with teachers and other students. Being empathetic to the students' school experiences can provide school leaders with the motivation to initiate innovative change and increase educational sustainability for future generations. The research findings provided insights and understandings on an 
alternative approach to producing change in the school setting leading to sustainable education. Innovative change based on close contact with the student experience could lead to a higher rate of student success and a higher rate for high school graduation by engaging school leaders in an empathetic design approach. Leaders, who gain empathy for student experiences could increase personal understanding of how students perceive the school day, how students characterize the socio-cultural environment of the school, and how students construct meaning from daily experiences.

\section{Acknowledgement}

We acknowledge the support of Dr. Mansureh Kebritchi research chair of the Center of Educational and Instruction Technology Research of the University.

\section{References}

Barrett, L. K., \& Long, B. V. (2012). The Moore method and the constructivist theory of learning: Was R. L. Moore a constructivist? Primus, 22(1), 75-84. doi: 10.1080/ 10511970.2010 .493548

Barry, M., \& Reschly, A. L. (2012). Longitudinal predictors of high school completion. School Psychology Quarterly, 27(2), 74-84. doi: 10.1037/a0029189

Barton, P. E. (2006). The dropout problem: Losing ground. Educational Leadership, 63(5), 14-18. Retrieved from http://www.ascd.org/publications/educationalleadership/feb06/vol63/num05/The-Dropout-Problem@-Losing-Ground.aspx

Bokova, T., \& Pluzhnikova, N. (2016). School concept as an instrument of socio-cultural changes in postmodern philosophy of education: From theory to practice. SHS Web of Conferences, 29, 1012. doi: 10.1051/shsconf/20162901012

Carmel-Gilfilen, C., \& Portillo, M. (2016). Designing with empathy. HERD: Health Environments Research \& Design Journal, 9(2), 130-146. doi: 1177/193758671 5592633

Common Core State Standards Initiative (2017). Preparing America's students for success. Retrieved from http://www.corestandards.org/

Daniel, S. M. (2015). Empathetic, critical integrations of multiple perspectives: A core practice for language teacher education? TESOL Journal, 6(1), 149-176. doi: 10.1002/tesj.184

Duckworth, A. L., Quinn, P. D., \& Tsukayama, E. (2012). What no child left behind leaves behind: The roles of IQ and self-control in predicting standardized achievement test scores and report card grades. Journal of Educational Psychology, 104(2), 439. doi: $10.1037 / \mathrm{a} 0026280$

Duggan, S. (2013) To an audience of "I", Qualitative Research Journal, 13(1), pp. 2532. doi: 10.1108/14439881311314513

El-Deghaidy, H. (2012). Education for sustainable development: Experiences from action research with science teachers. The Journal of the Institute of Sustainable Education, 3(1), 23-40. doi: 10.2478/v10230-012-0002-1

Elo, S., \& Kyngäs, H. (2008). The qualitative content analysis process. Journal of Advanced Nursing, 62(1), 107-115. doi: 10.1111/j.1365-2648.2007.04569.x

Eppley, K. (2015). Seven traps of the Common core state standards. Journal of Adolescent \& Adult Literacy, 59(2), 207-216. doi: 10.1002/jaal.431 
Eslamifar, A. (2014). A tool for empathetic user experience design (Doctoral dissertation). Retrieved from ProQuest Dissertations \& Theses Global. (Order No. 1570448).

Fleury, S. F., \& Garrison, J. W. (2014). Toward a new philosophical anthropology of education: Fuller considerations of social constructivism. Interchange (0826-4805), 45(1/2), 19-41. doi: 10.1007/s10780-014-9216-4

Hsieh, H., \& Shannon, S. E. (2005). Three approaches to qualitative content analysis. Qualitative Health Research, 15(9), 1277-1288. doi: 10.1177/1049732305276687

Husband, T., \& Hunt, C. (2015). A review of the empirical literature on No Child Left Behind from 2001 to 2010. Planning and Changing, 46(1), 212-254. Retrieved from https://www.researchgate.net/profile/Carolyn_Hunt/publication/293816670_ A_Review_of_the_Empirical_Literature_on_No_Child_Left_Behind_From_2001_ to_2010/links/56bbab5008ae47fa3956be3c.pdf?origin=publication_list

Irajzad, F., \& Shahriari, H. (2017). Student socioeconomic status and teacher stroke: A case of female students in Iran. Discourse and Communication for Sustainable Education, 8(1), 129-144. doi: 10.1515/dcse-2017-0010

Johnston, E., Rasmusson, X., Foyil, B., \& Shopland, P. (2017). Witnesses to transformation: Family member experiences providing individualized music to their relatives with dementia. Cogent Education, 4(1), doi: 10.1080/2331186X.2017.1362888

Kearney, M. S., \& Levine, P. B. (2016). Income inequality, social mobility, and the decision to drop out of high school. Brookings Papers on Economic Activity, 333396. doi: 10.3386/w20195

Khalifa, M. A., Gooden, M. A., \& Davis, J. E. (2016). Culturally responsive school leadership. Review of Educational Research, 86(4), 1272-1311, doi: 10.3102/ 0034654316630383

Kolko, J. (2010). Abductive thinking and sensemaking: The drivers of design synthesis. Design Issues, 26(1), 15-28. doi: 10.1162/desi.2010.26.1.15

Kosar, D., Kilinç, A. Ç., Koşar, S., Er, E., \& Öğgdem, Z. (2016). The relationship between teachers' perceptions of organizational culture and school capacity for change. Ĕ̈itim Bilimleri Araştırmalar Dergisi, 6(2), 39-59. doi: 10.12973/jesr.2016.62.3

Leonard, D., \& Rayport, J. F. (1997). Spark innovation through empathic design. Harvard Business Review, 75(6), 102-113. Retrieved from https://pdfs.semanticscholar.org/ b3d9/c137784343319b32dc9b8ba819e889882460.pdf

Maringe, F., Masinire, A., \& Nkambule, T. (2015). Distinctive features of schools in multiple deprived communities in South Africa. Educational Management Administration \& Leadership, 43(3), 363-385. doi: 10.1177/1741143215570303

Merriam, S. B. (2009). Qualitative research: A guide to design and implementation. San Francisco, CA: Jossey-Bass.

Mishra, R. K. (2014). Social constructivism and teaching of social science. Journal of Social Studies Education Research, 5(2), 1-13. doi: 10.17499/jsser.22283

National Center for Educational Statistics (April, 2017). The condition of education. Retrieved from nces.ed.gov

National Governors Association Center for Best Practices, Council of Chief State School Officers (2010). Common Core State Standards. National Governors Association Center for Best Practices, Council of Chief State School Officers, Washington DC.

O’Malley, M. P., Long, T. A., \& King, J. (2015). “What do you do all day?!” Journal of Cases in Educational Leadership, 18(2), 107-121. doi: 10.1177/15554589155 84673 
Packer, M. J., \& Goicoechea, J. (2000). Sociocultural and constructivist theories of learning: Ontology, not just epistemology. Educational Psychologist, 35(4), 227241. doi: 10.1207/S15326985EP3504_02

Shadow a Student (n.d.). Shadow a student challenge. Retrieved from shadowastudent.org

Smith, A., \& Thomson, M. M. (2014). Alternative education programmes: Synthesis and psychological perspectives. Educational Psychology in Practice, 30(2), 111119. doi: 10.1080/02667363.2014.891101

Tienken, C. C., \& Orlich, D. D. (2013). Translating the Common Core State Standards. AASA Journal of Scholarship \& Practice, 10(1), 3-7. Retrieved from https://www. aasa.org/.../Journals/.../Spring2013.FINAL_v3.pdf

U.S. Department of Education (2001). No Child Left Behind. Retrieved from https:// www2.ed.gov/policy/elsec/leg/esea02/index.html

Vaismoradi, M., Turunen, H., \& Bondas, T. (2013). Content analysis and thematic analysis: Implications for conducting a qualitative descriptive study. Nursing and Health Sciences, 15, 398-405. doi: 10.1111/nhs.12048

Walker, C. L., \& Shore, B. M. (2015). Understanding classroom roles in inquiry education: Linking role theory and social constructivism to the concept of role diversification. SAGE Open, 5(4), 215824401560758. doi: 10.1177/2158244015607584

Yin, R. K. (2013). Case study research: Design and methods (Applied social research methods) (5 $5^{\text {th }}$ ed.). Los Angeles, CA: Sage.

Zygmunt, T. (2016). Language education for sustainable development. Discourse and Communication for Sustainable Education, 7(1), 112-124. doi: 10.1515/dcse-20160008

Correspondence concerning this article should be addressed to Rita J. Hartman, Ed.D., Fellowship Faculty of Center for Educational and Instructional Technology Research, University of Phoenix, USA. Email: rjtrls@gmail.com 